\title{
ESTRUTURA SOCIAL E DIMORFISMO SEXUAL DE SYNALPHEUS BREVICARPUS (CARIDEA, ALPHEIDAE) HABITANDO ESPONJAS DYSIDEA SP. (DEMOSPONGIAE, DYSIDEIDAE)
}

\author{
Alves, D.F.R.., $;$; Simões, L.S.C. ${ }^{2}$; Nunes, A.D. ${ }^{2}$; Daltro, W.S. ${ }^{2}$ \& Andrade, M.A. ${ }^{2}$ \\ ${ }^{1}$ Universidade Estadual Paulista (UNESP), Campus Bauru, Laboratório de Biologia de Camarões Marinhos \\ e de Água Doce (LABCAM). \\ ${ }^{2}$ Universidade Federal de Sergipe (UFS), Campus São Cristóvão. Departamento de Biologia. \\ *Autor correspondente: douglas_biologo@yahoo.com.br
}

\begin{abstract}
O camarão de estalo Synalpheus brevicarpus (Herrick, 1891) pode viver livremente ou em associações simbióticas com os mais diversos hospedeiros. O presente estudo tem como objetivos descrever a organização social e o dimorfismo sexual de $S$. brevicarpus, em associação com esponjas Dysidea sp. Para tanto, 40 colônias de Dysidea sp. foram coletadas na região estuarina do rio Vaza-Barris, Sergipe, nordeste do Brasil. Cada esponja foi cuidadosamente fragmentada, os camarões foram individualizados em sacos plásticos e o volume da colônia de esponja foi mensurado. Os camarões foram identificados em relação à espécie e ao sexo e mensurados quanto ao comprimento da carapaça (CC), comprimento (CMQ) e altura (AMQ) da maior quela. As fêmeas ovígeras tiveram seus ovos contados. O volume das esponjas variou entre 10 e $260 \mathrm{ml}$, com média de $75 \pm$ $58,5 \mathrm{ml}$. Um relação positiva entre o volume da esponja e o número de camarões foi registrada $(\mathrm{F}=34,95 ; \mathrm{P}$ $<0,001)$. Em $67 \%$ das esponjas, foi encontrado ao menos um $S$. brevicarpus, sendo que em 3, 16 e 8 colônias foram registrados, respectivamente, um, dois, ou mais de três camarões. Dentre as 16 esponjas habitadas por dois camarões, casais heterossexuais foram registrados mais frequentemente $(\mathrm{N}=15)$ do que o esperado ao acaso $(N$ esperado $=5,87)$. Foi detectada uma correlação positiva entre os tamanhos de fêmeas e machos em casais $(\mathrm{F}=17.67 ; \mathrm{P}<0.001)$. Nas esponjas habitadas por três ou mais camarões, a razão sexual (RS) não foi estatisticamente diferente de $1: 1(R S=0,59 ; P=0,30)$. Um dimorfismo sexual acentuado foi registrado, tendo as fêmeas maiores tamanhos (CC) do que os machos $(t=-6,73$; $P<0,001)$, enquanto, os machos possuem uma quela $(\mathrm{CMQ}$ e $\mathrm{AMQ})$ maior que as fêmeas $(\mathrm{P}<0,001)$. A fecundidade de $S$. brevicarpus variou entre 4 e 361 ovos, com média de $108 \pm 111$ ovos. Foi verificada uma relação positiva entre o tamanho da carapaça das fêmeas e a fecundidade $(F=49,38 ; P<0,001)$. Os resultados aqui apresentados nos permitem sugerir que S. brevicarpus adota um sistema monogâmico, quando em associação com esponjas Dysidea sp. Tal sugestão é suportada pelos padrões de distribuição populacional, de ocupação do hospedeiro e de dimorfismo sexual. Entretanto, nas maiores colônias de esponja, S. brevicarpus adota um sistema social comunal ( $>3$ camarões por esponja), com diferentes casais defendendo distintas partes da esponja, i.e., reentrâncias e canais, como seus refúgios, onde vivem grande parte da vida adulta.
\end{abstract}

Palavras-chave: dimorfismo sexual, monogamia, simbiose, sociobiologia. 